\title{
О КЛАССИФИКАЦИИ УРОВНЕЙ ФУНКЦИОНИРОВАНИЯ РОДНЫХ ЯЗЫКОВ КОРЕННЫХ МАЛОЧИСЛЕННЫХ НАРОДОВ В ОБРАЗОВАТЕЛЬНОМ ПРОСТРАНСТВЕ
}

\section{CLASSIFICATION OF LEVELS OF FUNCTIONING OF NATIVE LANGUAGES \\ OF SMALL INDIGENOUS PEOPLES IN THE EDUCATIONAL ENVIRONMENT}

V. Unarova

Summary: The author considers the creation of a developing speech environment in native languages as one of the ways to develop, support and preserve the native language and improve the status of the native (ethnic) language in schools. The article presents the results of research in the field of education of indigenous peoples of the North, Siberia and the Far East of the Russian Federation.

The concept of «developing speech environment» is specified in the aspect of the research topic by studying and analyzing the literature on native languages of small indigenous peoples. The results of a remote survey of participants in educational relations (managers, teachers, parents) served as the basis for compiling a classification of the levels of functioning of native languages, consequently, the typology of schools by the level of functioning of their native language, and to design a model for creating a developing speech environment in native languages in schools located in places where indigenous peoples live.

The results obtained can serve as a methodological basis for the development of a didactic system aimed at activating, stimulating and developing students ' motivation to master their native (ethnic) language, speech activity, and communication activities in conditions of limited functioning of the native language or the lack of a natural speech environment in school, family, or society.

Keywords: native (ethnic) language, indigenous small people, developing speech environment, classification, typology of schools, model of developing speech environment.

\author{
Унарова Вилена Яковлевна \\ С.н.С., ФГБНУ «Институт национальных школ \\ Республики Саха (Якутия)» \\ vilena-86@mail.ru
}

Аннотация: В качестве одного из путей развития, поддержки и сохранения родного языка и повышения статуса родного (этнического) языка в школе автор рассматривает создание развивающей речевой среды на родных языках. В статье представлены результаты исследования в сфере образования коренных малочисленных народов Севера, Сибири и Дальнего Востока Российской Федерации.

Путем изучения и анализа литературы, посвященной вопросам родных языков коренных малочисленных народов, конкретизировано понятие «развивающая речевая среда» В аспекте темы исследования. Результаты дистанционного опроса участников образовательных отношений (руководителей, учителей, родителей) послужили основой для составления классификация уровней функционирования родных языков, следовательно, типологии школ по уровню функционирования в них родного языка, а также для проектирования модели создания развивающей речевой среды на родных языках в школах, расположенных в местах проживания коренных малочисленных народов.

Полученные результаты могут методологической базой для разработки дидактической системы, направленной на активизацию, стимулирование и развитие у обучающихся мотивации к овладению родным (этническим) языком, речевой активности, коммуникативной деятельности в условиях ограниченного функционирования родного языка/отсутствия естественной речевой среды в школе, семье, социуме.

Ключевые слова: родной (этнический) язык, коренные малочисленные народы, развивающая речевая среда, классификация, типология школ, модель развивающей речевой среды.

\section{Введение}

$\mathrm{H}$ а территории России живут 47 коренных малочисленных народов, 40 из них относятся к коренным малочисленным народам Севера, Сибири и Дальнего Востока (далее - КМНС) [3], в том числе 65\% проживают в сельской местности [4].
В настоящее время родным языком пользуются в общении в основном представители старшего поколения. Последние два поколения уже близки к тотальной утрате родного языка. Несмотря на рост этнического самосознания вынуждены признать, что этническая и языковая самоидентификация у большинства представителей КМНС не совпадают. За короткий исторический период нарушена естественная языковая преемственность поколений.

Статья подготовлена в рамках выполнения научно-исследовательской работы в ФГБНУ «Научно-исследовательский институт национальных школ Республики Саха (Якутия)» по государственному заданию Министерства просвещения Российской Федерации №073-00031-20-01 от 13 марта 2020 года. 


\section{Актуальность темы исследования}

Родные языки КМНС занимают особое место в системе образования. В качестве языка обучения языки КМНС перестали функционировать, прервана языковая преемственность между уровнями образования. Изучение родного языка КМНС понимается на сегодняшний день как изучение этнического языка, которым владеют не в такой степени, как носители родных языков из числа титульных народов (например, как татары, башкиры, якуты и т.д.). В школах на их изучение выделяется неравномерное (недостаточное) количество учебных часов (как предмета, элективного курса, факультатива, кружка), что обусловлено нехваткой педагогов-носителей, отсутствием современных учебно-методических изданий на языках и т.п. В условиях ограниченного функционирования родных языков в социуме, отсутствия языковой среды в школе, должной поддержки языка за пределами классного помещения (урока), процесс овладения речью на родном языке сильно затруднен.

Акцентируя внимание на таком проблемном поле, как «отсутствие языковой среды» и «низкая мотивация», отметим, что эти два компонента взаимообусловлены: если отсутствует языковая среда - нет и мотивации к овладению языком, отсутствует мотивация - не быть языковой среде. Назрела необходимость оказания качественной поддержки функционирования родных языков в образовательном пространстве, принятия мер по интенсификации речевой среды, создания условий для развития языков. В качестве одной из важных мер по развитию, поддержке и сохранению родных языков КМНС в школьной системе рассматриваем такое направление научно-исследовательской работы, как создание развивающей речевой среды (далее - РPС) в образовательных организациях, расположенных в местах традиционного проживания. В современных условиях естественная речевая среда (семейная, общественная, образовательная) требует особой поддержки. Отсутствие же естественной речевой среды в школах говорит о необходимости и целесообразности его создания искусственным путем как комплекса условий, приближенных к естественным.

Средовая педагогика охватывает как общеобразовательные, так и дошкольные организации, всех участников образовательных отношений и учитывает разные степени владения родным (этническим) языком, формы учебной деятельности и ресурсы сельской школы, которые могут быть использованы в создании специальной среды.

Целью исследования является научное обоснование необходимости и возможностей создания на уровне начального общего образования РPC, благоприятно воздействующей на изучение родного (этнического) языка, формирование мотивации к овладению им как у детей, так и у взрослых. Для достижения цели работы необходимо решить ряд первоочередных задач: 1) конкретизировать и теоретически обосновать понятийный аппарат в аспекте темы исследования, дать определение понятию PPC; 2) выявить предпосылки создания РPC в школах, составить классификацию уровней функционирования в них родного языка; 3) спроектировать модель РPС в школах (на уровне НОО), расположенных в местах традиционного проживания КМНС, в соответствии с их типами.

\section{Методы исследования}

Для решения поставленных задач и проверки исходных теоретических положений использовался комплекс теоретических и эмпирических методов исследования:

1. изучение и анализ научной литературы, нормативных и стратегических документов, посвященных языкам КMHC;

2. описательный метод - определение понятий «речевая среда», «языковая среда», формулирование нового определения понятия «развивающая речевая среда» в аспекте темы исследования;

3. классификация и типология;

4. моделирование проектируемой РPC;

5. анкетирование - дистанционный опрос руководителей образовательных организаций (инструментарий составлен на платформе Google), расположенных в местах проживания КМНС, учителей и родителей обучающихся начальных классов (электронные анкеты);

6. сравнительно-сопоставительный метод - анализ, обобщение, сравнение и сопоставление исходных теоретических и аналитических данных, а также полученных результатов дистанционного опроса.

\section{Материалы и результаты исследования}

В аспекте обозначенной темы исследование проведено с точки зрения трех позиций:

1. понятийного аппарата;

2. предпосылок и условий для создания РРС на родных языках (классификация уровней функционирования родных языков КМНС);

3. проектирования модели РPС на родных языках. Соответственно, получены первичные результаты по трем позициям, вытекающим из задач исследования, тем самым достигнута цель проведения исследования. Обобщим и опишем полученные результаты.

Позиция 1. Понятийный annapam. Теоретический анализ научной литературы привел нас к пониманию того, что в современной науке нет однозначного понимания понятия "развивающая речевая среда», его сущности и структуры, а относительно изучения язы- 
ков КМНС - и вовсе отсутствуют работы, посвященные данной проблематике. В основном встречаются термины «развивающая среда», в том числе «развивающая предметно-пространственная среда» (ФГОС ДО) при описании образовательной среды на уровне дошкольного образования, и «образовательная среда», в том числе «информационно-образовательная среда» (ФГОС НОO, ОOO, СОO) - на уровнях начального, основного и среднего общего образования. Также часто в научных трудах, посвященных проблеме обучения преимущественно иностранному языку, фигурируют термины «языковая среда» и «речевая среда». При этом четкого разграничения между последними терминами не существует. Отдельное внимание уделяется понятию «семейная среда».

Концептуальная база нашего понятийного аппарата построена на основе теории развивающего потенциала речевой среды Л.П. Федоренко. Термин «развивающая речевая среда» впервые встречается в работе Федоренко Л.П. [6; 9], на основе которой продолжена научная мысль, и реализован в школьной практике проект Багге М.Б. Она рассматривает школу как РPС и дает такое определение данного понятия: «Под развивающей речевой средой (термин Л.П. Федоренко) понимается среда, стимулирующая речевые коммуникации, среда, в которой развивающий потенциал не складывается стихийно, а носит планомерный и последовательный характер, направляет коммуникативную деятельность» [2], «развивающая речевая среда рассматривается как условие полноценного формирования мышления учащихся и становления их личности» [1].

Ее идея создания РРС как средства повышения мотивации в изучении русского языка детьми-инофонами базируется на системном подходе к организации такой среды с включением в деятельность всех субъектов образовательного процесса, которая способствует их интеллектуальному и общекультурному развитию, сохранению отношения к родной речи как к абсолютной ценности [2].

В рамках исследования представляем следующее определение данного понятия: развивающая речевая среда (как социально-педагогическая категория) - это подсреда образовательной среды, представляющая собой специально организованную дидактическую систему, направленную на активизацию, стимулирование и развитие у детей мотивации к овладению родным (этническим) языком, речевой активности, коммуникативной деятельности в процессе получения общего образования в условиях отсутствия речевой среды/ограниченного функционирования родного языка в жизни социума. Усвоение языка (теория) и речевая деятельность (практика) в таком ракурсе находятся на одном поле, во взаимодополнении. Именно в РРС изучение системы языка на уроке подкрепляется речевой практикой. Чем младше ребенок, тем больше ожидается эффекта и языковой перспективы.

Основная идея (концепция) создания РPC заключается в создании благоприятных условий для стимуляции речевой активности на родном (этническом) языке у обучающихся, не владеющих или слабо владеющих им, а также их родителей, и повышения статуса родного языка в образовательных организациях, расположенных в местах традиционного проживания КМНС. Таким образом, PPC - междисциплинарный феномен, с точки зрения педагогики, психологии, лингводидактики и социологии, который отражает специфику языковой ситуации КМНС.

Позиция 2. Классификация уровней функционирования родных языков в образовательном пространстве. В качестве одной из предпосылок и условий создания PPC считаем необходимость выявить уровень функционирования родного языка КМНС в образовательном пространстве. Особенность функционирования родного языка зависит и от общего состояния языка в мире (глобальный аспект), и от социолингвистической ситуации в отдельно взятом населенном пункте (локальный аспект).

В классификации ЮНЕСКО (Language Vitality and Endangerment) оценка уровня витальности языков мира представлена по 9 критериям, начиная от «межпоколенческой передачи языка», заканчивая «документированностью языка». Каждый критерий оценивается по 6-балльной шкале, или степеням опасности исчезновения, где 5 - находится в безопасности, 0 - язык исчез. Степени опасности исчезновения с цветовым обозначением представлены на интерактивном Атласе исчезающих языков мира ЮНЕСКО (www.unesco.org) [13]. Haпример, долганский язык обозначен желтым цветом, что означает «определенную угрозу» (definitely endangered), эвенский, эвенкийский, чукотский языки - оранжевым цветом, т.е. они находятся в «серьезной опасности» (severely endangered), юкагирский язык - красным цветом, т.е. он находится в «критическом состоянии» (critically endangered).

Оценка уровня витальности и цветовое кодирование также предложены в классификации Этнолога (Ethnologue) (www.ethnologue.com) [12] - наиболее известном справочнике по языкам мира, разрабатываемом и выпускаемом организацией SIL International. Этнолог аналогично ЮНЕСКО использует специальную шкалу для определения состояния языка - находится он в безопасности или вымирает. Используется 5 цветовых градаций, где: фиолетовый - институциональные языки (Institutional), синий - развивающиеся (Developing), зелёный - энергичные (Vigorous), жёлтые - в беде (In trouble), красные - умирают (Dying) и чёрные - вымерли (Extinct). Оценка состояния языка осуществляется от 
0 до 10, где 0 - язык хорошо используется, а 10 - язык относится к вымершим. Языки, которые находятся под реальной угрозой, начинаются в шкале от 7 баллов носители общаются между собой, но не передают язык детям, коммуникация этими языками сильно затруднена. К ним, например, относят эвенский, нивхский, ительменский, тофаларский, нанайский, негидальский, орокский, удэгейский, ульчский и другие языки.

В данном исследовании мы оперируем двумя группами факторов, имеющих количественные и качественные признаки и оказывающих влияние на уровень функционирования языка КMHC:

1. К внешним факторам относится языковая ситуация в селе, регионе (показатели: статус языка, нормативная закрепленность, госпрограммы; преобладающее поколение владеющих; наличие научной школы, методистов, СМИ, учреждение культуры, дополнительного образования; сельские мероприятия, языковой (общинный) клуб, традиционные промыслы; языковая преемственность уровней образования, т.е. изучение языка в дошкольной организации, продолжение изучения на последующих уровнях образования и т.п.).

2. Внутренние факторы зависят от внутришкольных обстоятельств и коммуникативной значимости общения между участниками образовательных отношений. Внутренние факторы могут быть подразделены на следующие параметры измерения: а) обучение и изучение языков в школе (основные показатели: доля изучающих родной язык в числе всех обучающихся, количество педагогов, форма учебной деятельности, локальные документы, наличие преемственности в изучении родного языка и т.п.); б) потенциал школы для создания PPC (этнокультурная предметно-развивающая среда; коммуникативно-речевая среда, речевое взаимодействие участников образовательных отношений: педагог-педагог, педагог-дети, педагог-родители; информационная языковая среда); в) речевая ситуация в школе (показатели: количество владеющих и не владеющих родным (этническим) языком, школьные мероприятия и т.п.); в) семейная речевая среда (показатели: поколение владеющих в семье, общение на уровне понимания, общение на бытовом уровне, общение в общественных местах, т.е. за пределами дома).

Отметим, что внешние факторы носят в значительной мере фоновый характер. Основное внимание обращено именно на внутренние факторы. Наша классификация построена на основе классификации уровней витальности ЮНЕСКО и классификации Этнолог (Ethonologue). Переработаны, адаптированы под образовательное пространство не только параметры и критерии, включающие множество факторов, но и цветовое решение, демонстрирующее уровень функционирования того или иного языка. Языки КМНС, согласно классификации ЮНЕСКО, относим к 3-0 степеням опасности исчезновения, соответственно классификация уровней функционирования родных языков состоит из 4 уровней (по шкале 3-0 баллов) по интенсивности: 1 уровень (высокий) - родной язык сохранен, хотя и находится под угрозой исчезновения (благоприятная (естественная) речевая среда); 2 уровень (средний) - родной язык в очень ослабленном состоянии, находится в серьезной опасности (ослабленная (частично естественная, есть в семье) речевая среда); 3 уровень (низкий) - родной язык в критическом состоянии, сильно ограничен во всех сферах (исчезающая (искусственная, практически нет в семье) речевая среда); 4 уровень (нулевой) - язык КМНС не функционирует в образовательном пространстве (тотальная утрата родного языка в семье, школе, социуме).

В качестве цветовой кодировки градации уровней функционирования родных языков КМНС опирались на классификацию Этнолога с учетом выделенных 4 уровней. Соответственно, цветовое обозначение начинается с зеленого цвета и предъявляется нами следующим образом:

1. уровень (высокий) - зеленый цвет;

2. уровень (средний) - желтый цвет;

3. уровень (низкий) - красный цвет;

4. уровень (нулевой) - серый цвет. При этом цветовая кодировка может быть градиентной, т.е. могут быть промежуточные цвета, переходящие от одного цвета в другой.

Составлению предлагаемой нами 4-хуровневой классификации функционирования родных языков КМНС в образовательном пространстве предшествовала обширная многоаспектная работа. Кроме того, путем проведения в 16 населенных пунктах 11 регионов России дистанционного опроса (руководителей, учителей и родителей обучающихся), а также анализа данных, представленных на официальных сайтах образовательных организаций, были скорректированы и конкретизированы критерии выявления уровней функционирования родных языков не только в образовательных организациях, но и в семьях обучающихся.

Позиция 3. Проектирование модели дидактической системы по созданию РPС. Перед проектированием модели РPС необходимо было в первую очередь выяснить, из каких компонентов она может состоять. При проектировании мы опирались на моделирование и проектирование развивающей среды В.А. Ясвина [11], М.Б. Багге [1; 2], теории школьного уклада (Тубельский [8]) и др., на ключевые принципы метаязыкового подхода в изучении языков (Unarova V.Y. [14]).

Ясвин А.В. на основе моделирования 4 типов обра- 
зовательной среды в историко-педагогическом аспекте (догматическая среда, безмятежная среда, карьерная среда, творческая среда) выделяет 4 компонента образовательной среды:

1. субъекты образовательного процесса;

2. социальный компонент;

3. пространственно-предметный компонент;

4. технологический (или психодидактический) компонент [11, С.173].

Багге М.Б. в структуре РРС также выделяет 4 компонента:

1. образовательная программа школы;

2. образовательные технологии;

3. внеучебная работа;

4. взаимодействие с внешними институтами [1].

Также в качестве компонентов современной образовательной среды выделяют такие компоненты, как:

1. предметно-пространственный;

2. цифровая информационно-образовательная среда;

3. взаимодействие между участниками;

4. структура образовательной программы [10].

Имеющаяся теоретико-методологическая база позволяют смоделировать возможности создания РPC на родных языках. При этом нельзя забывать, что модель может содержать как инвариантные компоненты, так и вариативные компоненты. Ключевыми фигурами в модели должны быть именно участники образовательных отношений - обучающиеся, и их родители, педагогический коллектив, администрация школы и другие организации, осуществляющие образовательную деятельность. В качестве компонентов дидактической системы создания РPС мы выделяем следующие:

1. этнокультурный предметно-развивающий компонент (материальное этноориентированное окружение);

2. коммуникативно-речевой компонент (речь педагога, речевое взаимодействие, коммуникация участников образовательных организаций);

3. информационный языковой компонент (языковое оформление пространства школы и ее территории).

Каждый компонент имеет свои составляющие: контент (например, лексический набор, речевые конструкции, фразы-клише, диалоги, тексты и т.д.), форму и средства (например, этапы урока, школьное мероприятие, мастерская, игровые атрибуты, панели «речевая фотозона», «древо языка», мобильный разговорник, громкоговоритель, мессенджер WatsApp, цифровые ресурсы и др.), методы и технологии (например, методы «посреднический диктант», «образовательная переменка», игровой метод, ИКТ-технологии, методика «мастер-ученик», частичная CLIL-технология, караоке-технология и т.п.). В купе эти составляющие направлены на повышение мотивации, познавательной активности детей (активизация фоновых знаний), приобщение к родной культуре, формирование и развитие речи на родном (этническом) языке, усвоение системы родного языка (развитие языковой способности). Они присутствуют как в самом школьном пространстве, урочной и внеурочной деятельности, деятельности педагогов, детей и родителей, так и во внешкольной деятельности (в дополнительном образовании, самообразовании).

В соответствии с составленной классификацией нами

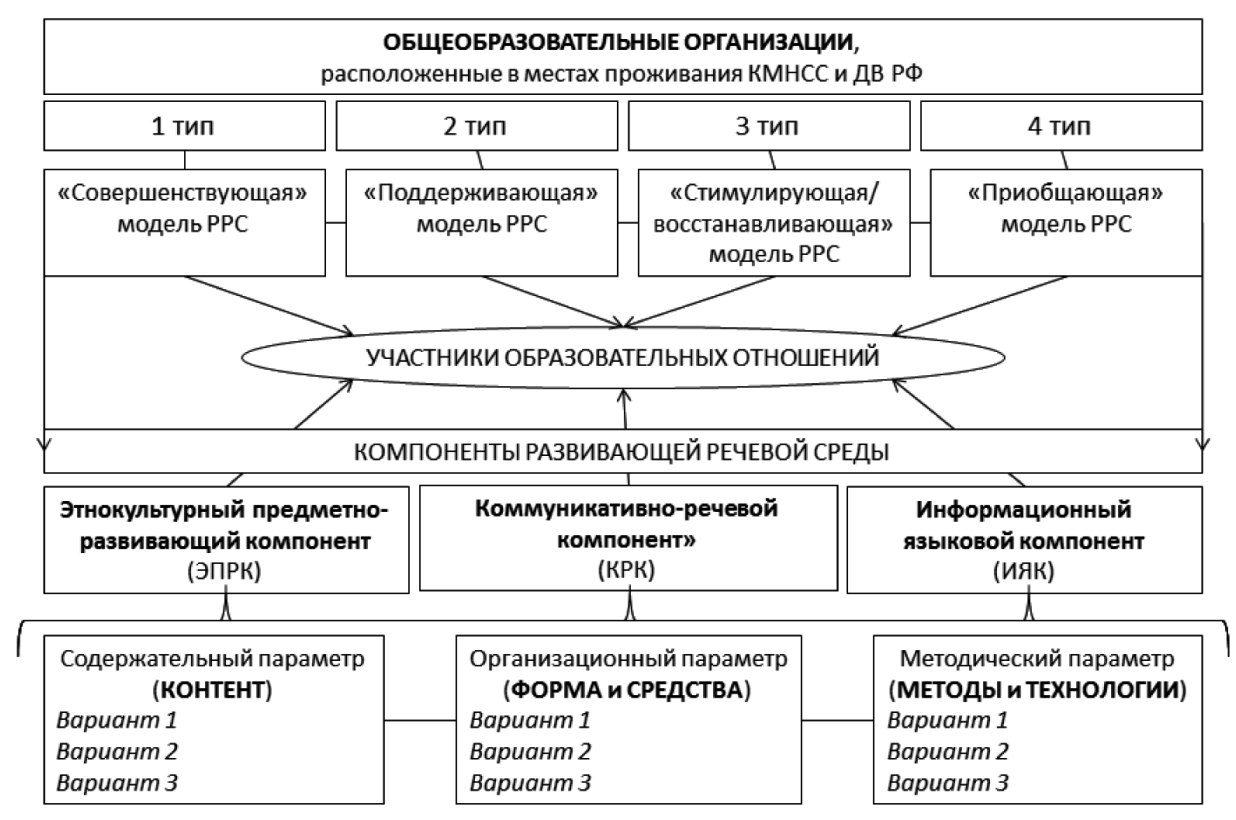

Рис. 1. Модель дидактической системы создания РPС на родных языках КМНС 
определены типы школ, обусловливающих стратегию проектирования и внедрения в дальнейшем дидактической системы РPC (см. Рис.1): тип 1 - соответствует высокому уровню=благоприятная речевая среда (необходимо внедрение «совершенствующей» модели РPС); тип 2 - соответствует среднему уровню=ослабленная речевая среда (необходима «поддерживающая» модель РРС); тип 3 - соответствует низкому уровню=исчезающая речевая среда (нужна «стимулирующая или восстанавливающая» модель РP(); тип 4 - соответствует нулевому уровню=нет речевой среды, т.е. в случаях, если:

1. в школе язык КМНС никогда не функционировал, но есть положительные тенденции, говорящие о намерениях изучить родной язык и культуру, ввести в образовательный процесс этнокультурный компонент;

2. в школе когда-то родной язык преподавался, имеется для возобновления минимальный потенциал. Здесь речь идет о «приобщающей» модели (приобщение в большей степени к этнической культуре), которая выстроена иначе, чем остальные три модели и требует больших организационно-методических ресурсов.

Таким образом, выявлены стратегии внедрения моделей РРС в зависимости от типа школы, в которой уровень функционирования родных языков может варьироваться от высокого до нулевого уровня. Тенденции функционирования родного языка в школе при этом могут быть трех видов: «устойчивая», «развивающаяся» и «деградирующая». Они могут быть выявлены путем включения в инструментарий вопросов, связанных с динамикой языковой ситуации в школе за последние 5-10 лет.

\section{Зак^ючение}

В качестве перспективных предложений, сформулированных на основе первичных результатов исследования, указываем следующие:

1. Развивающий потенциал образовательной организации может быть реализован в полной мере через введение «единого речевого режима», разработку «речевой программы» (программы создания РPC), обязательное введение статуса родного языка КМНС в локальный документ (Устав школы, Положение о языках образования).

2. Для родителей обучающихся необходимы реко- мендации по языковому воспитанию детей, речевому развитию, просветительские мероприятия, наглядно демонстрирующие важность владения родным языком, развития билингвизма, в том числе развития метаязыковых способностей.

3. Для сетевого взаимодействия школ, в которых внедряется модель создания РPС, а также мониторинга динамики функционирования родного языка в образовательных организациях с учетом языковой преемственности между уровнями образования (детский сад - начальная школа) необходимо формирование реестра школ и детских садов, расположенных в местах традиционного проживания КMHC, в которых изучаются родные языки.

4. В качестве дополнительной меры обеспечения этнокультурных потребностей детей в школе нужен тьютор, сопровождающий РPС образовательной организации (носитель языка, отвечающий квалификационным требованиям к работнику системы образования), за пределами школы - «мастер» (носитель языка, не обязательно с педагогическим образованием, достаточно наличия практического опыта, прохождения краткосрочных курсов).

Исследование положительного эффекта на усвоение речи на родном языке путем создания РРС требует длительного экспериментального наблюдения и изучения. Необходима диагностика и характеристика речевого развития детей «на входе» и «на выходе». При этом нельзя забывать о мотивационной составляющей всего процесса создания РРС. Важно выйти на уровень национально-русского билингвизма, актуализировать у школьников пассивный лексикон и речевой опыт на родном языке, полученный от окружения (на улице, в школе, услышанной речи, прочитанной книге), активизировать их собственные ресурсы на родном (этническом) языке во взаимосвязи и наравне с русским языком.

Миссия системы образования заключается в оказании содействия передаче языка подрастающему поколению, становлению билингвальной языковой личности обучающихся, владеющих родным языком в первую очередь, и осознающих себя как представитель конкретного народа, следовательно, как часть многонационального российского общества.

\section{ЛИТЕРАТУРА}

1. Багге М.Б. Развитие речемыслительной деятельности обучающихся в условиях речевой среды образовательного учреждения // Проблемы современного педагогического образования. 2016. №51-3. С.3-13.

2. Багге М.Б. Школа как развивающая речевая среда (из опыта работы образовательных учреждений Санкт-Петербурга) // Непрерывное образование в Санкт-Петербурге. 2015. №2 (2). С.81-85.

3. Единый перечень коренных малочисленных народов Российской Федерации (утвержден постановлением Правительства РФ от 24 марта 2000 года 
№255) [Электронный ресурс]. URL: https://base.garant.ru/181870/ (дата обращения: 29.04.2020).

4. Концепция устойчивого развития коренных малочисленных народов Севера, Сибири и Дальнего Востока Российской Федерации (утверждена распоряжением Правительства РФ от 4 февраля 2009 года №132-р) [Электронный ресурс]. URL: http://docs.cntd.ru/document/902142304 (дата 06 ращения: 14.05.2020).

5. Леханова Ф.М. Родные языки, литература и культура коренных малочисленных народов Севера, Сибири и Дальнего Востока в системе образования Российской Федерации: Сборник информационно-аналитических материалов / Ф.М. Леханова, Н.Н. Васильева, В.Я. Унарова. Якутск: Дани-Алмас, 2017. $220 \mathrm{c}$.

6. Методика развития речи детей дошкольного возраста / под ред. Л.П. Федоренко, Г.А. Фомичева, В.К. Лотарева. М., 1984. 240 с.

7. Пустогачева А.Ф. Современное состояние обучения и изучения родных языков коренных малочисленных народов Севера, Сибири и Дальнего Востока в системе образования Российской Федерации // История и педагогика образования. 2014. №2. С.41-46.

8. Тубельский А. Скрытое содержание образования и уклад школьной жизни. Народное образование: научно-методическая серия. 2007 . №9 (1372). С.205-211.

9. Федоренко Л.П. Закономерности усвоения родной речи. Москва: Просвещение, 1984.

10. Формирование современной образовательной среды (проект МГПУ, Корпорации «Российский учебник», авторский коллектив: Барсукова Е.М., Белолуцкая А.К., Иванова Е.В. и др., 2019 г.) [Электронный ресурс]. URL: https://director.rosuchebnik.ru/upload/service/director/fsos.pdf?fbclid=lwAR2Pwxg50_ ZK7ZSf4sVKj8bmTdEkgSI-vwsGrgAerxhWFpV2XhfZ3y8HLRI (дата обращения: 15.05.2020).

11. Ясвин В.А. Школа как развивающая среда (монография). М.: Институт научной информации и мониторинга РАО, 2010. 358 с. (Серия: Научно-издательский проект в поддержку национальной образовательной инициативы «Наша новая школа»).

12. Eberhard David M., Gary F. Simons, and Charles D. Fennig (eds.). 2020. Ethnologue: Languages of the World. Twenty-third edition. Dallas, Texas: SIL International. Online version: https://www.ethnologue.com/

13. Moseley Christopher (ed.). 2010. Atlas of the World's Languages in Danger, 3rd edn. Paris, UNESCO Publishing, Online version: http://www.unesco.org/culture/en/ endangeredlanguages/atlas

14. Unarova V.Y., Hamraeva E.A. 2018. Targeted Metalinguistic Development of Primary School Students: a Case Study of Yakut-Russian Bilingualism. Modern Journal of Language Teaching Methods, Volume 8, Issue 12. Pp. 450-458. Retrieved from: https://apps.webofknowledge.com/full_record.do?product=W0S\&search_mod $\mathrm{e}=$ GeneralSearch\&qid=13\&SID=D3CkmmgIEydGis2gz3L\&page $=1 \& d 0 c=1$

(с) Унарова Вилена Яковлевна (vilena-86@mail.ru).

Журнал «Современная наука: актуальные проблемы теории и практики»

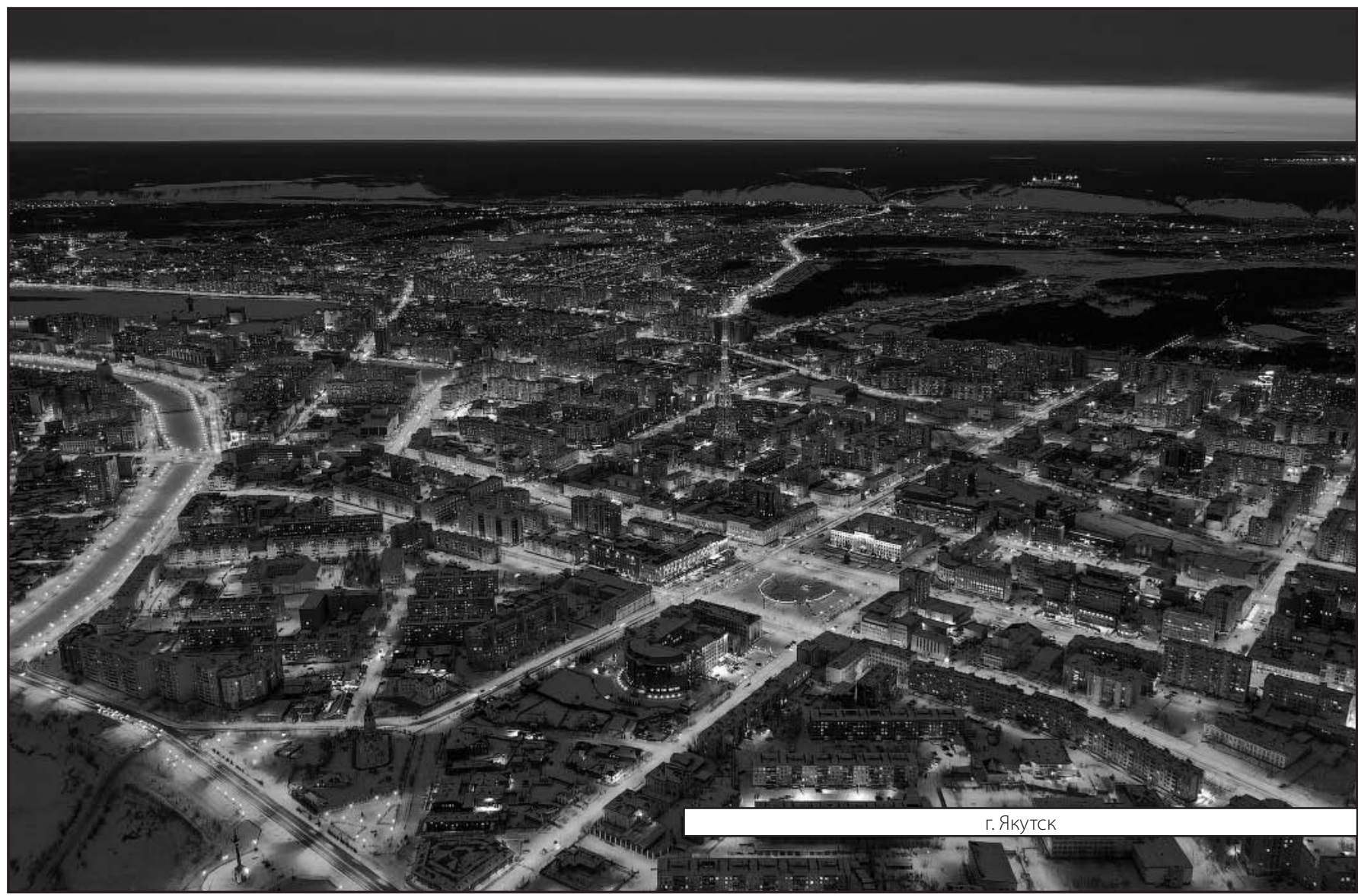

